Article

\title{
Structural Characterization of Lignocresols from Transgenic and Wild-Type Switchgrass
}

\author{
Hao Ren ${ }^{1}$, Wenyuan Tian ${ }^{1}$, Fan Shu ${ }^{1}$, Dongliang $X u^{1}$, Chunxiang Fu ${ }^{2}$ and Huamin Zhai ${ }^{1, *}$ \\ 1 Jiangsu Co-Innovation Center for Efficient Processing and Utilization of Forest Resources, \\ Jiangsu Provincial Key Lab of Pulp and Paper Science and Technology, Nanjing Forestry University, No.159, \\ Longpan Rd., Xuanwu District, Nanjing 210037, China; renhao@njfu.edu.cn (H.R.); \\ wy_tian0224@163.com (W.T.); shufan2326@126.com (F.S.); xd11218@126.com (D.X.) \\ 2 Qingdao Institute of Bioenergy and Bioprocess Technology, Chinese Academy of Science, \\ Qingdao 266101, China; fucx@qibebt.ac.cn \\ * Correspondence: hzhai@njfu.edu.cn; Tel.: +86-138-1395-0657
}

Received: 20 May 2018; Accepted: 29 June 2018; Published: 2 July 2018

\begin{abstract}
Cafferic acid-O-methyltransferases (COMT) down-regulated transgenic and wild-type switchgrass were separated into lignocresols (LCs) and sugars by a phase separation method involving $72 \%$ sulfuric acid and cresol. The isolated LCs were characterized by FTIR, GPC, ${ }^{1} \mathrm{H}$ NMR and 2D-HSQC to understand potential structural modification caused by transgenic engineering lignin or phase separation treatment. No significant changes were found in terms of molecular weights and the amount of incorporated $p$-cresols between transgenic and wild-type switchgrass LCs. However, the compositions, ratios of syringyl (S) units to guaiacyl (G) units, were changed significantly leading to decrease in $S$ units and increase in $G$ units for transgenic switchgrass LC. The benzodioxane structures and 5-hydroxyguaiacyl units were observed in the 2D-HSQC implied that 5-hydroxyconiferyl alcohol was incorporated into lignin as a result of COMT-down-regulation in the transgenic process.
\end{abstract}

Keywords: switchgrass; lignocresols; transgenic sample; structural characterization

\section{Introduction}

In recent years, because of the rapid growth of the global population, rapid economic development, and improved standards of living, the demand for energy has increased dramatically worldwide [1]. The use of fossil fuels increases the emission of harmful substances such as $\mathrm{SO}_{2}, \mathrm{CO}_{2}$, and dust, leading to exacerbated environmental pollution and global climate change [2]. How to overcome the energy shortage and environmental pollution has become a great challenge for the present and future. Therefore, renewable and clean energy has become the focus of attention. Plant-based bioenergy has the advantages of less environmental pollution, renewable nature, potential low-cost, and wide applications [3], being considered as an ideal choice for the future energy generation [4]. In the process of cellulosic ethanol production, cellulose and polysaccharides are hydrolyzed to fermentable sugars, whereas lignins are left over as insoluble residues that have not been utilized efficiently in a significant scale due to their complex structures.

Switchgrass (Panicun virgatum L.) is a dedicated energy crop identified by the U.S. department of energy [5]. Fu et al. reported that down-regulation of the switchgrass cafferic acid 3-O-methyltransferase (COMT) gene modestly decreases lignin content, reduces the syringyl:guaiacyl lignin monomer ratio, improves forage quality, and increases ethanol yield by up to $38 \%$ using the conventional biomass fermentation processes. The down-regulated lines require less severe pretreatment and $300-400 \%$ lower cellulase dosages for equivalent product yields using simultaneous saccharification and fermentation with yeast [6]. 
To realize the comprehensive and economic industrial-scale production of biomass energy, high value-added utilization of lignin has been long focused. However, when considering the application of lignins, it is very important to track the changes in lignin structure during the transgenic process. In addition, some bits of important structures would be lost during the acidic or alkaline or ball milling preparation process. In this study, COMT regulated switchgrass was compared to its wild-type with respect to the structural characterization of lignocresols (LCs) after being subjected to a high acidic phase separation method [7]. Benzodioxane structures and 5-hydroxyguaiacyl units which were formed during the transgenic process were proved to be stable under the phase separation conditions and their characteristic C-H correlated signals in 2D-HSQC NMR spectra were identified distinctly. This work demonstrated again that phase separation is an effective method for separating lignins from carbohydrate in a biorefinery concept. The separated lignin derivatives, LCs, maintained most of their $\beta$-ether linkages and had high hydroxyl content due to the incorporation of cresol.

\section{Materials and Methods}

\subsection{Materials}

p-Cresol (chemical pure, $\mathrm{CP}$ ), $72 \%$ sulfuric acid (CP), solid $\mathrm{KBr}$ in solid (analytical reagent, AR grade), tetrahydrofuran (THF), acetone, and diethyl-ether (CP) were purchased from Sinopharm Chemical Reagent Co. (Shanghai, China). The 60-mesh pass powder of COMT down-regulated switchgrass (transgenic) and wild-type switchgrass (control) were provided by Dr. Fu Chunxiang of the Qingdao Institute of Bioenergy and Bioprocess Technology, Chinese Academy of Sciences. The chemical components of transgenic and control samples were as follows: moisture, $10.36 \%$ and $10.12 \%$; Klason lignin, $17.21 \%$ and $20.56 \%$; acid soluble lignin, $1.96 \%$ and $1.98 \%$; cold water extractives, $10.39 \%$ and $10.93 \%$; hot water extractives, $15.19 \%$ and $16.37 \% ; 1 \% \mathrm{NaOH}$ extractives, $33.37 \%$ and $32.29 \%$; and ash, $1.72 \%$ and $1.68 \%$, respectively.

\subsection{Phase Separation Procedure}

$p$-Cresol (10 mL/g biomass) was added to switchgrass meals with stirring. After $10 \mathrm{~min}, 72 \%$ sulfuric acid ( $20 \mathrm{~mL} / \mathrm{g}$ biomass) was added to the mixture and the vigorous stirring was continued at room temperature for the prescribed time. The resultant mixture was let stand for $10 \mathrm{~min}$. The separated cresol phase was added drop-wise to an excess $(200 \mathrm{~mL})$ of ethyl ether with vigorous stirring. The precipitates were collected and dissolved in acetone $(80 \mathrm{~mL})$, and insoluble materials were removed by centrifugation. The acetone solution was concentrated to $10 \mathrm{~mL}$ under reduced pressure and added drop-wise to an excess $(200 \mathrm{~mL})$ of ethyl ether with stirring. The precipitated lignin derivative (LCs, ether-insoluble) was collected by centrifugation and dried over $\mathrm{P}_{2} \mathrm{O}_{5}$ after evaporating the solvent. The ether soluble fractions were not accounted into the yield of LCs. The schematic model of phase separation is shown in Figure 1. 


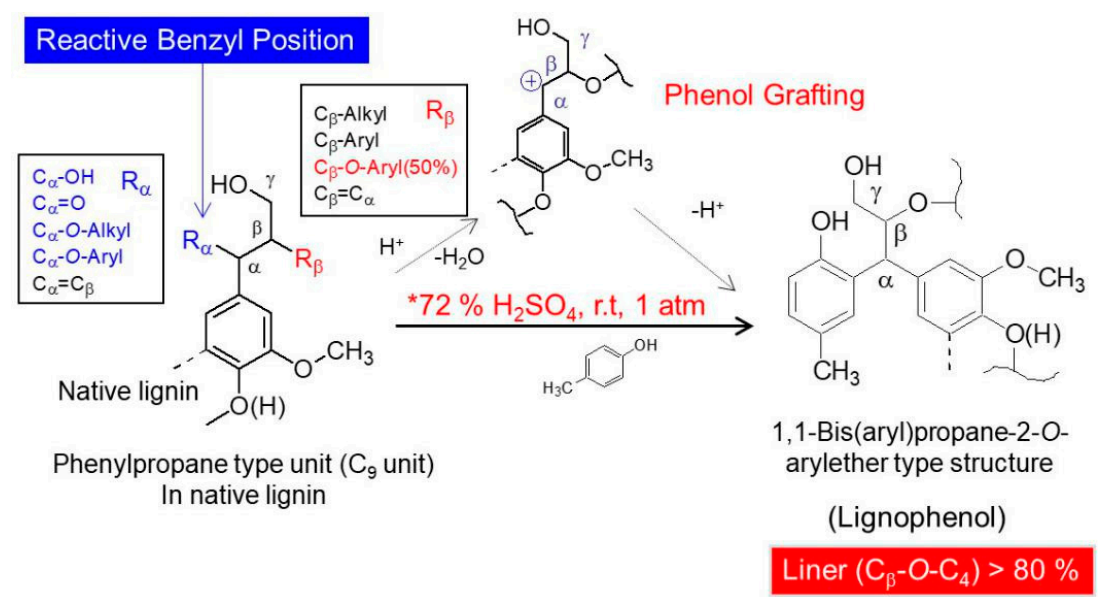

Figure 1. A schematic model of phase separation system [8].

\subsection{Characterization of LCS}

The FT-IR spectra of LCs were obtained on a Bruker VERTEX80 Spectroscope (Bruker, Berlin, Germany) using $\mathrm{KBr}$ discs. The spectra were recorded in the range from $400 \mathrm{~cm}^{-1}$ to $4000 \mathrm{~cm}^{-1}$ with a resolution of $4 \mathrm{~cm}^{-1}$ over 32 scans. Calibration for the weight-average molecular weight $\left(M_{\mathrm{w}}\right)$, number-average molecular weight $\left(M_{\mathrm{n}}\right)$, polydispersity $\left(M_{\mathrm{w}} / M_{\mathrm{n}}\right)$, and the gel permeation chromatography (GPC) of lignins were determined on a PL-GPC50 plus Integrated GPC System (Varian Inc., Nagoya, Japan) equipped with a Waters 2410 RID detector. Sepax Mono-GPC columns $(100 \AA, 300 \AA, 500 \AA, 10 \mathrm{~mm}$ ID $\times 300 \mathrm{~mm})$ were connected in a series and tetrahydrofunan (THF) was used as an eluent under the flow rate of $1.0 \mathrm{~mL} / \mathrm{min}$. A series of polystyrene (Mw: 200,000, 100,000, $500,000,30,000,20,000,10,000,4300,2000,108)$ was used as standard to make calibration line.

${ }^{1} \mathrm{H}$ NMR spectra of LCs in $\mathrm{C}_{5} \mathrm{D}_{5} \mathrm{~N}-\mathrm{CDCl}_{3}(1: 3, v / v)$ and acetylated $\mathrm{LCs}$ in $\mathrm{CDCl}_{3}$ were recorded on a $300 \mathrm{MHz}$ NMR spectrometer. $p$-Nitrobenzaldehyde was used as the internal reference for the measurements. The amounts of incorporated cresol were calculated based on the signal intensity of its methyl protons (1.6-2.4 ppm) against aromatic protons (7.8-8.4 ppm) of internal standard ( $p$-nitrobenzaldehyde) on ${ }^{1} \mathrm{H}$ NMR spectra of original lignocresols. The hydroxyl group contents were determined from acetyl proton signals on ${ }^{1} \mathrm{H}$ NMR spectra of acetylated lignocresols. The cresolic methyl proton signals overlapped in the region of acetyl protons were estimated based on the relative intensity of cresol methyl to aromatic proton signals in the spectra of original lignocresols [9]. The methoxy content were calculated according to the methods reported by Aberu and Freire (1995) [10,11].

Elemental analysis was performed on the lignin samples using a Perkin Elmer 2400 II Elemental Analyser instrument (PerkinElmer, Shanghai, China). In preparing the samples for analysis, first they were dried at $40{ }^{\circ} \mathrm{C}$ overnight by vacuum drying oven to remove any moisture. To measure carbon, hydrogen, nitrogen and sulfur contents, 1-2 mg samples were encapsulated in a tin container. The analysis results were obtained via gas chromatography, and compared with those of standard materials.

2D-HSQC NMR spectra were recorded on a $600 \mathrm{MHz}$ NMR spectrometer (Avance III, Bruker, Bern, Switzerland) equipped with a cryogenically-cooled $5 \mathrm{~mm}$ TCI gradient probe with inverse geometry at $25{ }^{\circ} \mathrm{C}$ [12]. A portion of each lignin sample $(60 \mathrm{mg})$ was dissolved in DMSO-d6 $(0.6 \mathrm{~mL})$ as the deuterated NMR solvent. The central solvent peak was used as an internal reference $(\delta \mathrm{C} / \delta \mathrm{H} 39.5 / 2.50)$. The HSQC experiments were obtained using Bruker's "hsqcetgpsp.2" adiabatic pulse program with spectral widths from 0 to $12 \mathrm{ppm}(9615 \mathrm{~Hz})$ and from 0 to $165 \mathrm{ppm}(24,900 \mathrm{~Hz})$ for the ${ }^{1} \mathrm{H}$ and ${ }^{13} \mathrm{C}$ dimensions, respectively. The number of collected complex points was 2048 for the ${ }^{1} \mathrm{H}$ dimension with a recycle delay (d1) of $1.5 \mathrm{~s}, 64$ transients for the HSQC spectra and 256 time increments in the ${ }^{13} \mathrm{C}$ dimension resulting in an overall experiment time of $18 \mathrm{~h} \mathrm{[13].} \mathrm{A} \mathrm{1JC-H} \mathrm{value} \mathrm{of} 145 \mathrm{~Hz}$ was employed. 
Prior to Fourier transformation, the data matrices were zero-filled to 1024 points in the ${ }^{13} \mathrm{C}$ dimension. A semiquantitative analysis of the intensity of the HSQC signals was then performed using Bruker's Topspin 2.1 processing software, and the integral method reported by Rio et al. was employed [14].

\section{Results and Discussions}

\subsection{Yields of LCs from Switchgrass through Phase Separation}

The yields of LCs from transgenic and control sample are shown in Table 1. Because the cell wall of herbaceous plants was relatively bulky compared to woody plants, several reaction times (10 $\mathrm{min}, 20 \mathrm{~min}, 30 \mathrm{~min}$, and $60 \mathrm{~min}$ ) were selected to produce LCs from the transgenic and wild type samples. Both samples showed the maximum yield when the treatment time was $30 \mathrm{~min}$ in phase separation and the yields of LCs from transgenic and control switchgrass were $71.0 \%$ and $57.4 \%$, respectively. This indicated that the yield of LCs was much higher than that from MWL, although it was lower than the LCs yields from woody plants [11]. This might be attributed to the loose cell wall structure of herbaceous plants and a lower degree of lignification compared to wood [15-17]. During the phase separation process, the lignin skeleton was selectively cleaved, resulting in many relatively small molecular lignin products $[7,8]$. After centrifugation, the LCs were collected in the organic phase, and part of the small molecule products was thought to be lost during the following purification process using diethyl ether and acetone. In Table 1, it can be observed that the yield increased gradually with the extension of reaction time from $10 \mathrm{~min}$ to $30 \mathrm{~min}$, and slightly decreased after $30 \mathrm{~min}$. To explain this phenomenon, it was considered that, at the beginning, as the time of phase separation increased, the frequency of cresol introduced increased gradually, and the yield of LCs increased. After $30 \mathrm{~min}$, the obtained LCs would further degrade under acidic conditions leading to an increase in the molecular components lost during the subsequent refining process using organic solvents. In summary, for the transgenic and control switchgrass, 30 min was a good reaction time for phase separation.

Table 1. Yields of lignocresols from transgenic and control lignin sample.

\begin{tabular}{ccccc}
\hline Sample & \multicolumn{4}{c}{ Yield \% (Based on Klason Lignin) } \\
\hline (Reaction Time) & $\mathbf{1 0}$ in & 20 min & 30 min & 60 min \\
\hline Transgenic & $53.75 \pm 0.12$ & $56.89 \pm 0.13$ & $71.01 \pm 0.12$ & $54.85 \pm 0.15$ \\
Control & $44.46 \pm 0.15$ & $44.89 \pm 0.10$ & $57.39 \pm 0.13$ & $43.87 \pm 0.14$ \\
\hline
\end{tabular}

\subsection{FTIR Spectra of Switchgrass LCs}

The FTIR spectra of LCs from transgenic and control switchgrass are shown in Figure 2. The peaks derived from syringyl propane units in the lignin skeleton were at 1325, 1220, and $1130 \mathrm{~cm}^{-1}$, and the peaks derived from guaiacyl propane units were clearly visible at 1270 and $1040 \mathrm{~cm}^{-1}$. In addition, there was a larger absorption peak at $3425 \mathrm{~cm}^{-1}$ derived from hydroxyl groups, at $1730 \mathrm{~cm}^{-1}$ from ester bond on the $\gamma$-position, and at $815 \mathrm{~cm}^{-1}$ there was an absorption peak due to the angular vibration of ortho-hydrogen on the benzene ring of the introduced $p$-cresol [15]. In the FTIR spectra, the structural characteristics of transgenic and control switchgrass were not significantly different, which also showed no significant difference compared to LCs from other herbaceous plants such as bamboo [16]. This suggested that the lignin units in switchgrass were the same as those in other herbaceous plants. In the transgenic plant, the numbers and ratios of lignin basic structural units (GSH units) may be changed, but lignin skeleton structure had not been changed. 


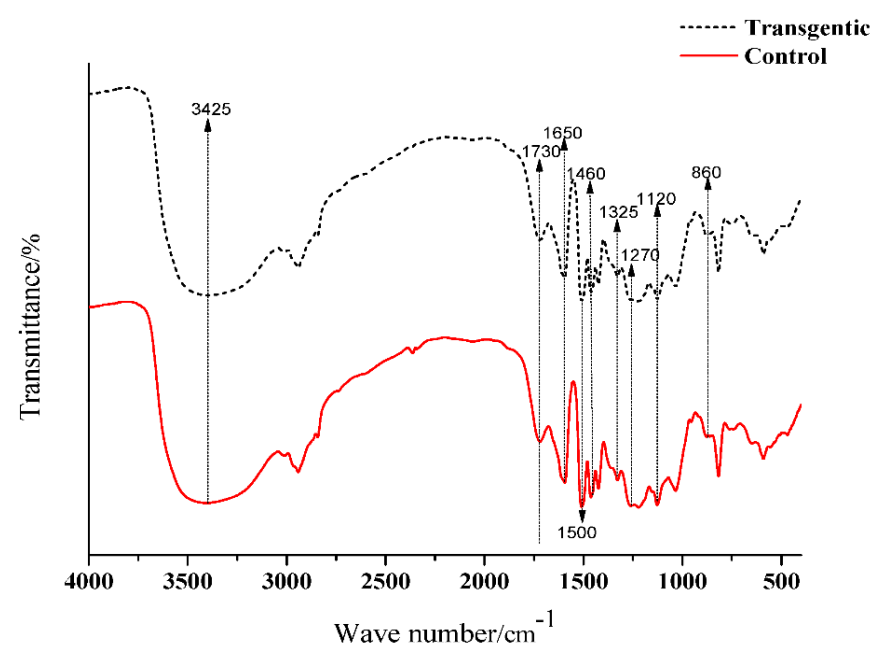

Figure 2. FTIR spectra of switchgrass LCs.

\subsection{Molecular Weights of LCs and Amounts of Incorporated p-Cresols}

The molecular weights, amounts of combined cresols, and hydroxyl groups of LCs are shown in Table 2. There was no significant difference in the molecular weight and the ratio of distribution between transgenic and control switchgrass. The polydispersity of the molecular weights of LCs were all close to 1, indicating that the size of the molecular chain was more uniform. After acetylation, the molecular weights of both samples increased significantly, because the amounts of hydroxyl groups (calculated based on Figures 3 and 4 ) are high in LCs. The amounts of introduced $p$-cresols on $\mathrm{C} \alpha$ in both samples were ca. $0.8 \mathrm{~mol} / \mathrm{C}_{9}$, which was consistent with the data reported for other kinds of herbaceous materials, and higher than the average level $\left(0.7 \mathrm{~mol} / \mathrm{C}_{9}\right)$ in softwood $[7,9]$. This again indicated that the structure of herbaceous plants was relatively loose, and that under the phase separation conditions, the reaction accessibilities and reactivity were superior to those of woody plants $[16,17]$.

Table 2. Molecular weight and functional groups of LCs.

\begin{tabular}{ccccccc}
\hline Sample & $\boldsymbol{M}_{\mathbf{w}}$ & $\boldsymbol{M}_{\mathbf{n}}$ & $\boldsymbol{M}_{\mathbf{w}} / \boldsymbol{M}_{\mathbf{n}}$ & $\begin{array}{c}\text { Combined } \\
\text { Cresol (mol/C } \mathbf{9})\end{array}$ & $\begin{array}{c}\text { PhOH } \\
\left(\mathbf{m o l} / \mathbf{C}_{\mathbf{9}}\right)\end{array}$ & $\begin{array}{c}\text { AliOH } \\
\left(\mathbf{m o l} / \mathbf{C}_{\mathbf{9}}\right)\end{array}$ \\
\hline $\begin{array}{c}\text { Transgenic } \\
\text { Control }\end{array}$ & $3547 \pm 23$ & $2087 \pm 28$ & 1.70 & 0.84 & 1.12 & 1.06 \\
Acetylated-Transgenic & $3444 \pm 42$ & $2464 \pm 37$ & 1.40 & 0.85 & 1.20 & 1.13 \\
Acetylated-Control & $4354 \pm 45$ & $2822 \pm 32$ & 1.54 & - & - & - \\
\hline
\end{tabular}

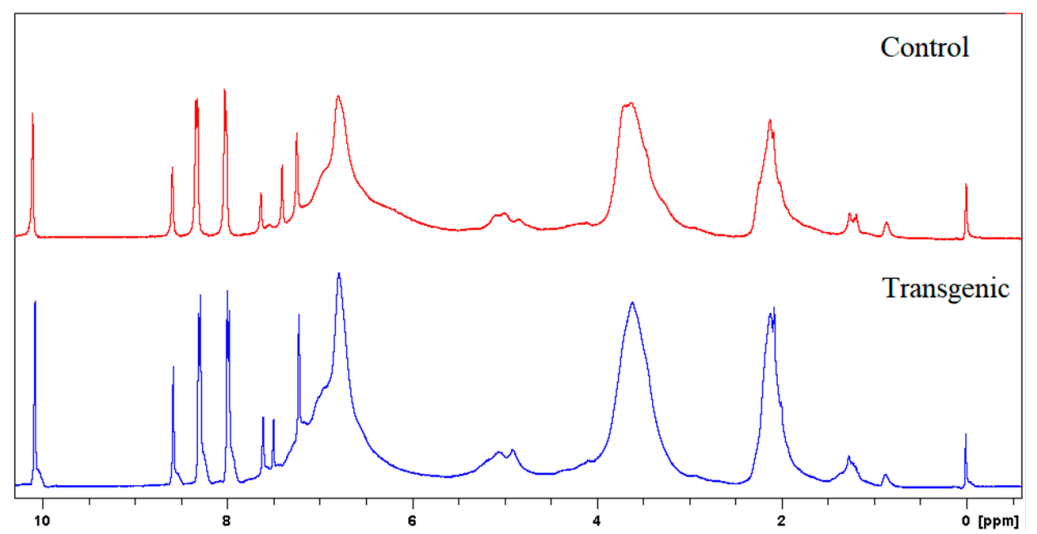

Figure 3. ${ }^{1} \mathrm{H}$ NMR spectra of LCs. 


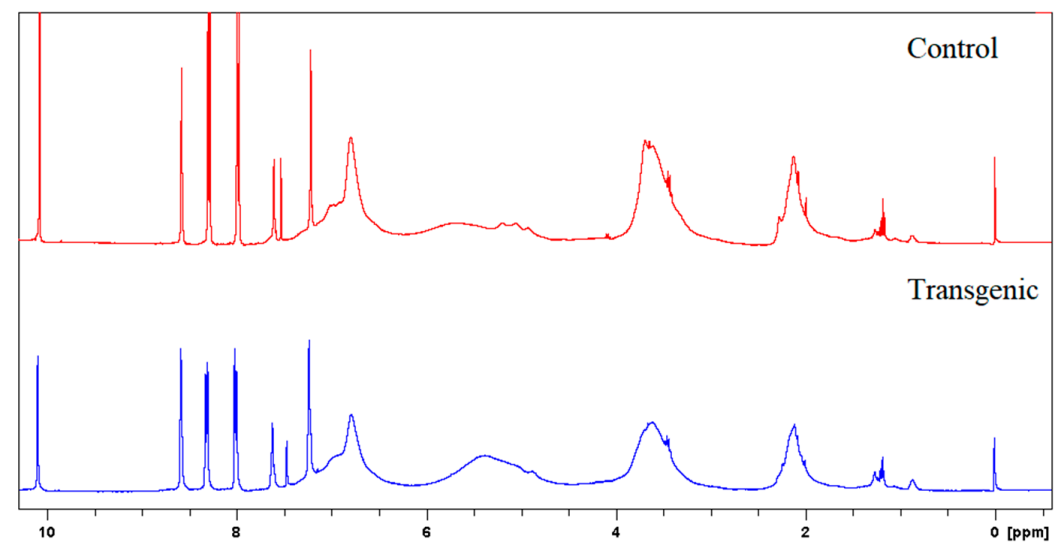

Figure 4. ${ }^{1} \mathrm{H}$ NMR spectra of acetylated LCs.

\subsection{Elemental Analysis and Methoxyl Content}

The elemental analysis results for the lignins are shown in Table 3. The data show that the carbon and hydrogen contents increase from control to transgenic switchgrass. In the transgenic sample, the nitrogen content is higher than that in the control sample, whereas the sulfur content is lower. Nitrogen may be originated from the enzyme during the transgenic treatment process and sulfur may be originating from the residual sulfuric acid during phase separation. In lignin chemistry, the empirical formula of the macromolecule is commonly presented as a hypothetical hydroxyphenyl structural unit. This is known as the $\mathrm{C}_{9}$ formula, with six carbon atoms in the benzene ring plus three carbon atoms making up the propyl side-chain. The results are shown in Table 3. The methoxyl group contents decreased from the control to transgenic samples. In the transgenic sample, the number of methoxyl groups is close to 1 per $C_{9}$ formula, indicating that the syringyl units had largely been decreased by the COMT down-regulation. This is due to the decreased activity of COMT enzyme that is responsible for methylating 5-hydroxyconiferaldyhye (leading to sinapyl alcohol) eventually to produce syringyl lignin units. As the results the acumination of 5-hydroxyconiferyl units (forming benzodioxane structures) resulted in decrease of $S$ units, hence, the $S / G$ ratio decreased $[6,18,19]$.

Table 3. Chemical composition of switchgrass LCs.

\begin{tabular}{cccccccc}
\hline & \multicolumn{9}{c}{ Analytical Composition (\%) } & \multirow{2}{*}{ Empirical Formula } \\
\cline { 2 - 6 } & $\mathbf{C}$ & $\mathbf{H}$ & $\mathbf{O}$ & $\mathbf{N}$ & $\mathbf{S}$ & $\mathbf{O C H}_{3}$ & \\
\hline Transgenic & 66.76 & 6.29 & 28.83 & 2.75 & 0.37 & 18.10 & $\mathrm{C}_{9} \mathrm{H}_{8.22} \mathrm{O}_{2.2} \mathrm{~N}_{0.35} \mathrm{~S}_{0.02}\left(\mathrm{OCH}_{3}\right)_{1.05}$ \\
Control & 62.92 & 5.97 & 28.45 & 2.27 & 1.39 & 19.58 & $\mathrm{C}_{9} \mathrm{H}_{7.97} \mathrm{O}_{2.1} \mathrm{~N}_{0.32} \mathrm{~S}_{0.08}\left(\mathrm{OCH}_{3}\right)_{1.23}$ \\
\hline
\end{tabular}

\subsection{D-HSQC NMR Spectra of LCs from Transgenic and Control Switchgrass}

The side-chain regions $(\delta \mathrm{C} / \delta \mathrm{H} 18-25 / 1.8-2.5, \delta \mathrm{C} / \delta \mathrm{H} 50-90 / 2.5-6.0)$ and aromatic ring region $(\delta \mathrm{C} / \delta \mathrm{H} 90-160 / 6.0-8.0)$ in the 2D-HSQC NMR spectra of LCs from transgenic and control switchgrass are shown in Figure 5, and the relevant signal attribution is shown in Table 4. The relative quantitative method was used for determination of various structural units, as shown in Table 5, and the molecular structure of the main basic units is shown in Figure 6. Wild-type switchgrass has guaiacyl units $(\mathrm{G}, 48.42 \%)$, syringyl units $(\mathrm{S}, 41.22 \%)$, and $p$-hydroxybenzene units $(\mathrm{H}, 10.36 \%)$ related signals in the aromatic ring region. The $\mathrm{S} / \mathrm{G}$ ratio is 0.85 . The transgenic switchgrass also has signals related to guaiacyl units $(\mathrm{G}, 69.46 \%)$, syringyl units $(\mathrm{S}, 19.70 \%)$ and $p$-hydroxybenzene units $(\mathrm{H}, 10.84 \%)$ in the aromatic ring region, and the $\mathrm{S} / \mathrm{G}$ ratio is 0.28 . These results indicate that lignins from transgenic and control switchgrass are typical GSH lignins, and that the $S$ unit of switchgrass was decreased significantly in the transgene. The $\beta-O-4$ alkyl-aryl ethers in lignocresol (A) produced from original 
$\beta-O-4$ alkyl-aryl ethers (A) and those with acylated $\gamma$-OH with $p$-coumaric acid ( $\mathrm{A}^{\prime}$ ) were observed in the side-chain region of both transgenic and control switchgrass. It is interesting to see that some phenylcoumarane structures (IC) and resinol structures (B) survived such an acidic treatment and the other typical structures were also observed in the side-chain region of both transgenic and control switchgrass. The relative ratios of $\beta-O-4, \beta-5$, and $\beta-\beta$ linkages in transgenic switchgrass LCs were $74.51 \%, 19.34 \%$ and $6.14 \%$, and those in control switchgrass LCs were $80.72 \%, 14.56 \%$ and $4.68 \%$, respectively. Upon comparison, the $\beta-5$ structure was found to be higher in transgenic switchgrass LCs than that in control LCs whereas the $\beta-O-4$ structure was found to be lower, which is consistent with their composition results. In addition, related signals of precursor structures such as $p$-hydroxycinnamyl alcohol end-groups (F) and its acylated moiety $\left(\mathrm{F}^{\prime}\right)$, ferulates $(\mathrm{FA})$ and $p$-coumarates $(p C A)$ were also observed.

In general, COMT down-regulated transgenic switchgrass lignin demonstrated a decrease in the syringyl (S):guaiacyl $(\mathrm{G})$ ratio and the $p$-coumarate:ferulate ratio (Table 5). The amount of total free phenolic $\mathrm{OH}$ groups in transgenic LCs was comparable with that in control samples, along with benzodioxane units $\left(D_{\alpha, \beta}\right.$ signals in Table 4$)$ or catechyl units $\left(C_{2,6}\right.$ signals in Table 4$)$ formed in the transgenic sample. Furthermore, COMT down-regulation did not significantly change lignin's molecular weights. These results are consistent with the data reported previously [20]. Although the native lignin structures had been changed during the phase separation, the semi-quantified compositions and interunit linkage distributions in LCs were basically representative of those before treatment, which allows them to be used to assess the changes of GSH units during the transgenic treatment.
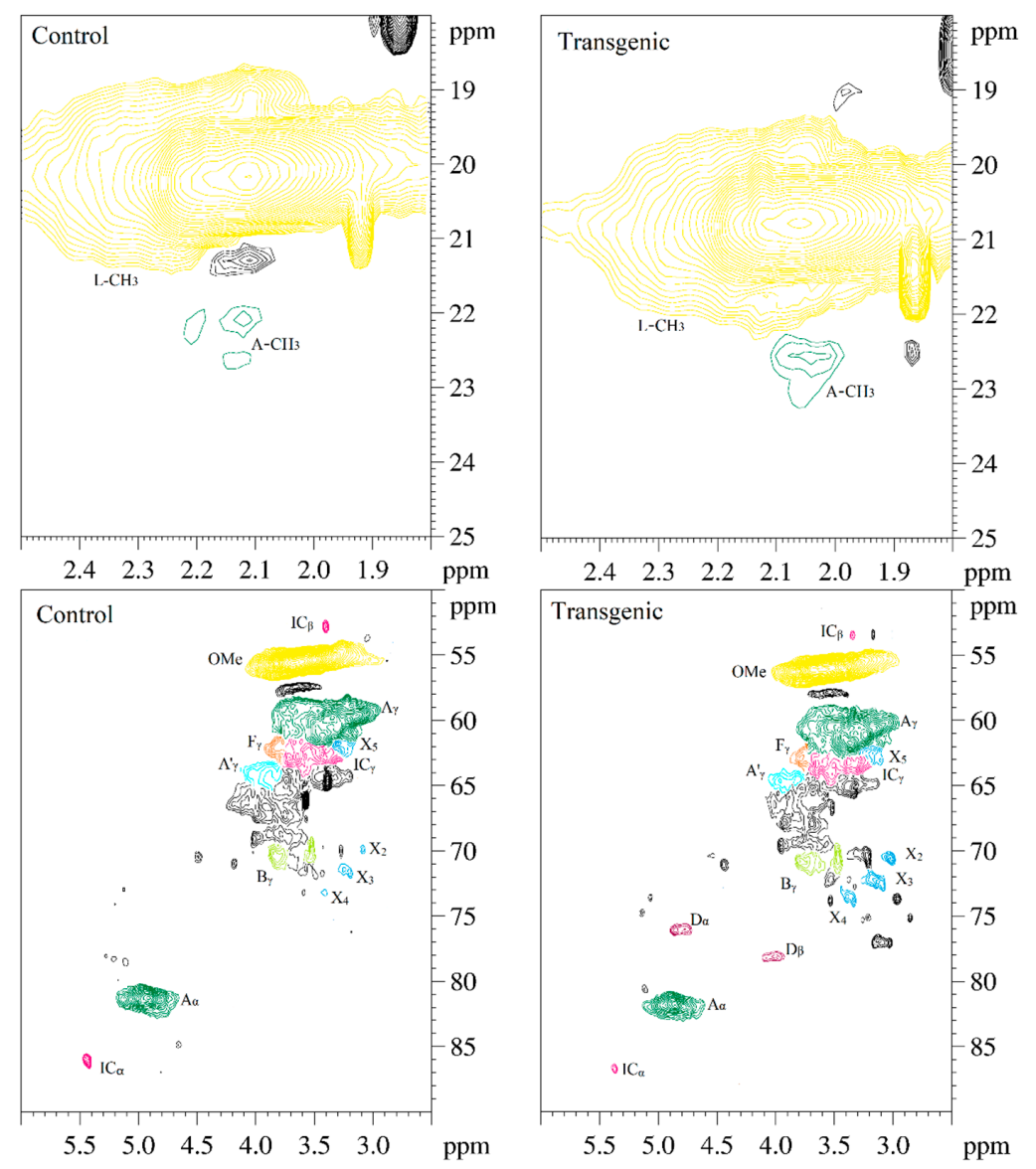

Figure 5. Cont. 

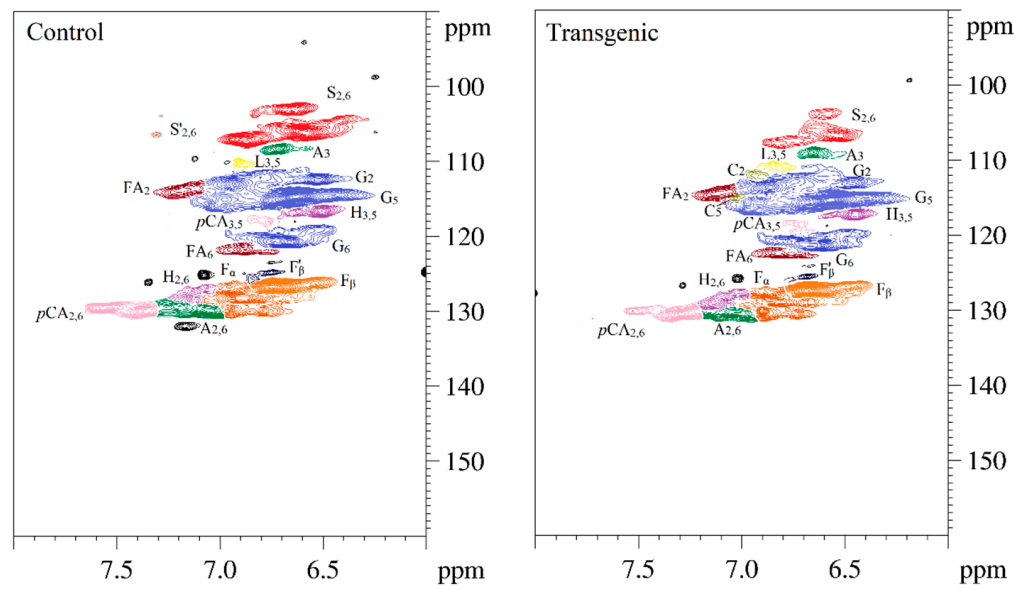

Figure 5. The 2D-HSQC NMR spectra of LCs from transgenic and control switchgrass.

Table 4. The 2D-HSQC NMR attribution of switchgrass LCs.

\begin{tabular}{|c|c|c|c|}
\hline Lable & $\delta_{C} / \delta_{H}(p p m)^{a}$ & $\delta_{\mathrm{C}} / \delta_{\mathrm{H}}(\mathrm{ppm})^{\mathrm{b}}$ & Assignment \\
\hline $\mathrm{A}-\mathrm{CH}_{3}$ & $22.02 / 2.12$ & $22.5 / 2.05$ & $\mathrm{C}-\mathrm{H}$ in lignocresol- $\mathrm{CH}_{3}(\mathrm{~A})$ \\
\hline $\mathrm{IC}_{\beta}$ & $52.75 / 3.40$ & $53.45 / 3.34$ & $\mathrm{C}_{\beta}-\mathrm{H}_{\beta}$ in phenylcoumaran substructures (IC) \\
\hline OMe & $55.54 / 3.67$ & $56.07 / 3.59$ & $\mathrm{C}-\mathrm{H}$ in methoxyls $(\mathrm{OMe})$ \\
\hline $\mathrm{A}_{\gamma}$ & $61.07 / 3.42$ & $61.73 / 3.36$ & $\mathrm{C}_{\gamma}-\mathrm{H}_{\gamma}$ in $\beta-\mathrm{O}-4$ substructure of lignocresol (A) \\
\hline $\mathrm{A}_{\gamma}^{\prime}$ & $64.24 / 4.03$ & $64.63 / 3.96$ & $\mathrm{C}_{\gamma}-\mathrm{H}_{\gamma}$ in $\gamma$-hydroxylated $\beta-O-4$ substructures $\left(\mathrm{A}^{\prime}\right)$ \\
\hline $\mathrm{F}_{\gamma}$ & $62.05 / 3.81$ & $62.91 / 3.78$ & $\mathrm{C}_{\gamma}-\mathrm{H}_{\gamma}$ in $p$-hydroxycinnamyl alcohol $(\mathrm{F})$ \\
\hline $\mathrm{IC}_{\gamma}$ & $62.62 / 3.57$ & $63.26 / 3.65$ & $\mathrm{C}_{\gamma}-\mathrm{H}_{\gamma}$ in phenylcoumaran substructures (IC) \\
\hline $\mathrm{B}_{\gamma}$ & $70.29 / 3.83$ & $70.82 / 3.79$ & $\mathrm{C}_{\gamma}-\mathrm{H}_{\gamma}$ in $\beta-\beta$ (resinol) substructures (B) \\
\hline $\mathrm{B}_{\gamma}$ & $69.68 / 3.52$ & $70.55 / 3.46$ & $\mathrm{C}_{\gamma}-\mathrm{H}_{\gamma}$ in $\beta-\beta$ (resinol) substructures (B) \\
\hline$X_{2}$ & $69.86 / 3.08$ & $70.54 / 3.02$ & $\mathrm{C}_{2}-\mathrm{H}_{2}$ in $\beta-\mathrm{D}-\mathrm{xylopyranoside}(\mathrm{X})$ \\
\hline$x_{3}$ & $71.66 / 3.19$ & $72.26 / 3.14$ & $\mathrm{C}_{3}-\mathrm{H}_{3}$ in $\beta-\mathrm{D}-\mathrm{xylopyranoside}(\mathrm{X})$ \\
\hline$X_{4}$ & $73.20 / 3.41$ & $73.69 / 3.36$ & $\mathrm{C}_{4}-\mathrm{H}_{4}$ in $\beta-\mathrm{D}-\mathrm{xylopyranoside}(\mathrm{X})$ \\
\hline$X_{5}$ & $61.68 / 3.29$ & $63.05 / 3.10$ & $\mathrm{C}_{5}-\mathrm{H}_{5}$ in $\beta-\mathrm{D}-\mathrm{xylopyranoside}(\mathrm{X})$ \\
\hline $\mathrm{D}_{\alpha}$ & ND & $76.2 / 4.84$ & $\mathrm{C}_{\alpha}-\mathrm{H}_{\alpha}$ in benzodioxane substructures (D) \\
\hline$D_{\beta}$ & ND & $78.6 / 4.10$ & $\mathrm{C}_{\beta}-\mathrm{H}_{\beta}$ in benzodioxane substructures (D) \\
\hline $\mathrm{A}_{\alpha}$ & $81.17 / 4.91$ & $81.71 / 4.86$ & $\mathrm{C}_{\alpha}-\mathrm{H}_{\alpha}$ in lignocresol (A) \\
\hline $\mathrm{IC}_{\alpha}$ & $86.07 / 5.43$ & $86.61 / 5.37$ & $\mathrm{C}_{\alpha}-\mathrm{H}_{\alpha}$ in phenylcoumaran substructures (IC) \\
\hline $\mathrm{S}_{2,6}$ & $106.1 / 6.58$ & $106.7 / 6.53$ & $\mathrm{C}_{2,6}-\mathrm{H}_{2,6}$ in syringyl units $(\mathrm{S})$ \\
\hline $\mathrm{S}_{2,6}^{\prime \prime}$ & $106.2 / 7.30$ & ND & $\mathrm{C}_{2,6}-\mathrm{H}_{2,6}, \mathrm{C}(\alpha)=\mathrm{O}$ in syringyl units $\left(\mathrm{S}^{\prime}\right)$ \\
\hline $\mathrm{G}_{2}$ & $112.9 / 6.91$ & $113.6 / 6.86$ & $\mathrm{C}_{2}-\mathrm{H}_{2}$ in guaiacyl units $(\mathrm{G})$ \\
\hline $\mathrm{G}_{5}$ & $114.6 / 6.63$ & $115.3 / 6.57$ & $\mathrm{C}_{5}-\mathrm{H}_{5}$ in guaiacyl units $(\mathrm{G})$ \\
\hline $\mathrm{G}_{6}$ & $120.6 / 6.66$ & $119.8 / 6.50$ & $\mathrm{C}_{6}-\mathrm{H}_{6}$ in guaiacyl units $(\mathrm{G})$ \\
\hline $\mathrm{H}_{3,5}$ & $116.6 / 6.50$ & $117.3 / 6.45$ & $\mathrm{C}_{3,5}-\mathrm{H}_{3,5}$ in $p$-hydroxyphenyl units $(\mathrm{H})$ \\
\hline $\mathrm{H}_{2,6}$ & $129.7 / 7.11$ & $129.1 / 7.07$ & $\mathrm{C}_{2,6}-\mathrm{H}_{2,6}$ in $p$-hydroxyphenyl units $(\mathrm{H})$ \\
\hline $\mathrm{C}_{2}$ & ND & $112.2 / 6.90$ & $\mathrm{C}_{2}-\mathrm{H}_{2}$ in catechyl units $(\mathrm{C})$ \\
\hline $\mathrm{C}_{5}$ & ND & $115.1 / 7.04$ & $\mathrm{C}_{5}-\mathrm{H}_{5}$ in catechyl units $(\mathrm{C})$ \\
\hline$A_{2,6}$ & $129.8 / 7.04$ & $130.2 / 7.02$ & $\mathrm{C}_{2,6}-\mathrm{H}_{2,6}$ in lignocresol (A) \\
\hline $\mathrm{A}_{3}$ & $108.3 / 6.71$ & $108.9 / 6.65$ & $\mathrm{C}_{3}-\mathrm{H}_{3}$ in lignocresol $(\mathrm{A})$ \\
\hline $\mathrm{L}_{3,5}$ & $110.2 / 6.90$ & $110.8 / 6.84$ & $\mathrm{C}_{3,5}-\mathrm{H}_{3,5}$ in cresol $(\mathrm{L})$ \\
\hline$p \mathrm{CA}_{2,6}$ & $130.0 / 7.35$ & $130.5 / 7.29$ & $\mathrm{C}_{2,6}-\mathrm{H}_{2,6}$ in $p$-coumarate ( $\left.p \mathrm{CA}\right)$ \\
\hline$p \mathrm{CA}_{3,5}$ & $118.0 / 6.76$ & $118.7 / 6.71$ & $\mathrm{C}_{3,5}-\mathrm{H}_{3,5}$ in $p$-coumarate $(p \mathrm{CA})$ \\
\hline $\mathrm{FA}_{2}$ & $113.6 / 7.12$ & $114.4 / 7.11$ & $\mathrm{C}_{2}-\mathrm{H}_{2}$ in ferulate (FA) \\
\hline $\mathrm{FA}_{6}$ & $121.8 / 6.87$ & $122.3 / 6.82$ & $\mathrm{C}_{6}-\mathrm{H}_{6}$ in ferulate (FA) \\
\hline $\mathrm{F}_{\alpha}$ & $128.1 / 6.88$ & $128.8 / 6.82$ & $\mathrm{C}_{\alpha}-\mathrm{H}_{\alpha}$ in $p$-hydroxycinnamyl alcohol $(\mathrm{F})$ \\
\hline $\mathrm{F}_{\beta}$ & $126.6 / 6.74$ & $127.3 / 6.69$ & $\mathrm{C}_{\beta}-\mathrm{H}_{\beta}$ in $p$-hydroxycinnamyl alcohol (F) \\
\hline $\mathrm{F}_{\beta}^{\prime}$ & $124.8 / 6.74$ & $125.4 / 6.68$ & $\mathrm{C}_{\beta}-\mathrm{H}_{\beta}$ in cinnamaldehyde end groups $\left(\mathrm{F}^{\prime}\right)$ \\
\hline
\end{tabular}

$\delta_{\mathrm{C}} / \delta_{\mathrm{H}}(\mathrm{ppm})^{\mathrm{a}}$, the HSQC spectra assignments of control switchgrass lignocresol sample. $\delta_{\mathrm{C}} / \delta_{\mathrm{H}}(\mathrm{ppm})^{\mathrm{b}}$, the HSQC spectra assignments of transgenic switchgrass lignocresol sample. ND, no detected. 
Table 5. The units and linkages proportion of switchgrass LCs.

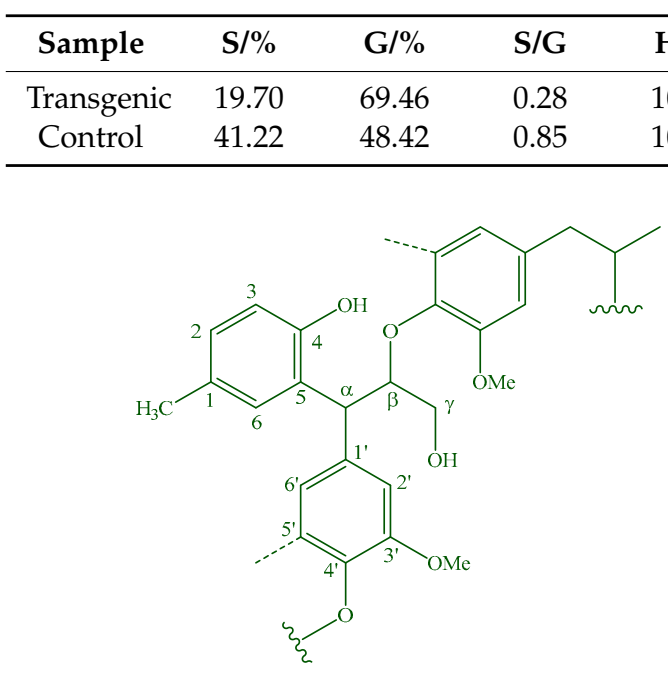

A
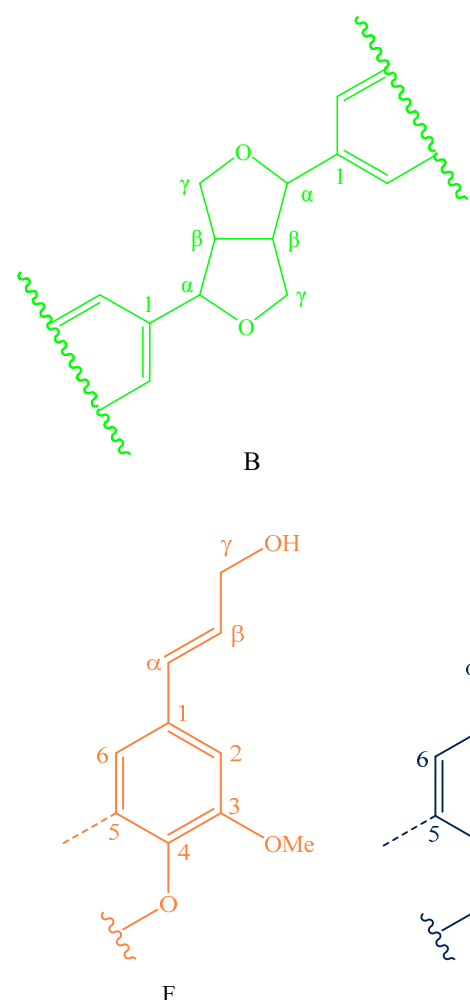

F

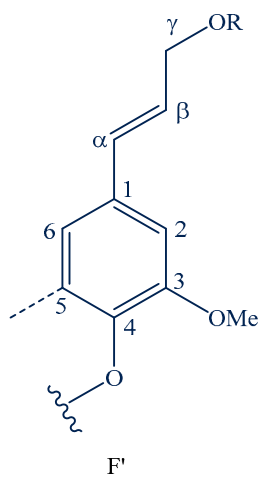

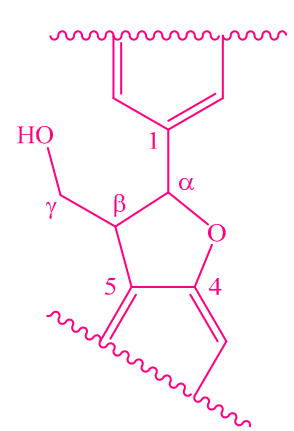

IC

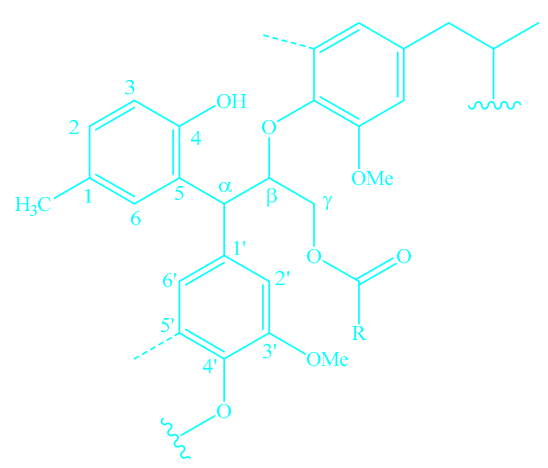

$\mathrm{A}^{\prime}$

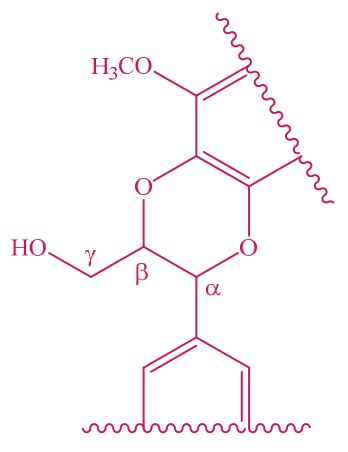

D<smiles>COc1cc(C=CC(=O)O)ccc1O</smiles>

FA

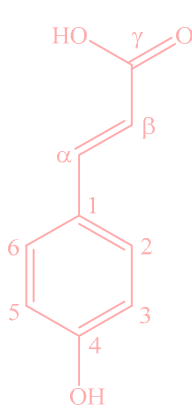

$p \mathrm{CA}$

Figure 6. Cont. 
<smiles>[R]Oc1cc(C(C)=O)cc(OC)c1OC</smiles>

$\mathrm{S}$

S'<smiles>COc1ccc(C)cc1OC</smiles>

G<smiles>COc1ccc(OC)cc1</smiles>

$\mathrm{H}$

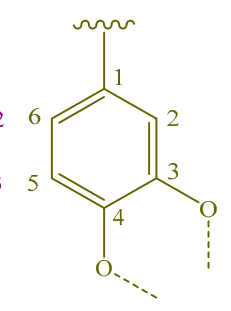

$\mathrm{C}$<smiles>COC1OC(O)C(C)C(O)C1O</smiles>

$\mathrm{X}$

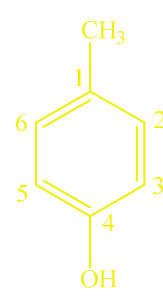

$\mathrm{L}$

Figure 6. Main classical structures in the lignin preparations: (A) lignocresol; (A') $\beta-O-4$ alkyl-aryl ethers with acylated $\gamma-\mathrm{OH}$ with $p$-coumaric acid; (B) resinol structures formed by $\beta-\beta / \alpha-O-\gamma / \gamma-O-\alpha$ linkages; (IC) phenylcoumarane structures formed by $\beta-5 / \alpha-O-4$ linkages; (D) benzodioxane substructures; (F) $p$-hydroxycinnamyl alcohol end-groups; $\left(\mathbf{F}^{\prime}\right) p$-hydroxycinnamyl alcohol end-groups acylated at the $\gamma$-OH; (FA) ferulates; ( $p$ CA)p-coumarates; (S) syringyl units; ( $\left.\mathbf{S}^{\prime}\right)$ oxidized syringyl units bearing a carbonyl at $\mathrm{C} \alpha$; $(\mathbf{G})$ guaiacyl units; $(\mathbf{H})$-hydroxyphenyl units; $(\mathbf{C})$ catechyl units; (X) xylopyranoside; and (L) $p$-cresol.

\section{Conclusions}

Phase separation method was demonstrated to have some advantages when applying to fractionate switchgrass biomass into carbohydrate and lignin derivatives, LCs. Although native lignin structures (mainly $\alpha$-hydroxyl groups of $\beta$-aryl ethers) were greatly modified in the phase separation process, almost all interunit linkages and lignin structural units remained in the products LCs. Although the molecular weight of LCs from transgenic sample was close to that of LC from the control, semi-quantified results from HSQC analysis indicated that COMT down-regulated transgenic switchgrass has less $S$ units (lower $S / G$ ratios) compared to the control sample. Benzodioxane structures formed from 5-hydroxyconiferyl alcohol in transgenic samples survived the phase separation. Due to the incorporation of cresol into LCs during the phase treatment, the isolated LCs contained high amount of hydroxyl group (mainly phenolic) implying that these LCs could be used for many applications.

Author Contributions: The manuscript was completed through contributions of all authors. H.R. and W.T. originated the overall motivation of the work and participated in the discussion the experimental plan and results. F.S. designed the schematic model structures and performed the phase separation experiments. D.X. analyzed the data. H.R. and F.S. wrote the paper. C.F. provided the switchgrass samples and the basic analysis data of them. H.Z. modified the paper and gave some advice.

Funding: This research received no external funding.

Acknowledgments: The authors are grateful for the support of the Innovation Projects for College Students of JiangSu Province (Project No. 201710298039Z). The work was also supported by the Nanjing Forestry University Outstanding Youth Fund (NLJQ2015-5) and the Priority Academic Program Development of Jiangsu Higher Education Institutions (PAPD), China.

Conflicts of Interest: The authors declare no conflicts of interest. 


\section{References}

1. Mcginnis, R.L.; Elimelech, M. Global challenges in energy and water supply: The promise of engineered osmosis. Environ. Sci. Technol. 2008, 42, 8625-8629. [CrossRef]

2. Dorian, J.P.; Franssen, H.T.; Simbeck, D.R. Global challenges in energy. Energy Policy 2006, 34, $1984-1991$. [CrossRef]

3. Calvin, M. Solar energy by photosynthesis. Science 1974, 184, 375-381. [CrossRef] [PubMed]

4. Ragauskasa, J.; Williamsc, K.; Davison, B.H. The path forward for biofuels and biomaterials. Science 2006, 311, 484-489. [CrossRef] [PubMed]

5. Mclaughlin, S.B.; Kszos, L.A. Development of switchgrass (Panicum virgatum) as a bioenergy feedstock in the United States. Biomass Bioenergy 2006, 28, 515-535. [CrossRef]

6. Fu, C.X.; Mielenz, J.R.; Xiao, X.R. Genetix manipulation of lignin reduces recalcitrance and improves ethanol production from switchgrass. Proc. Natl. Acad. Sci. USA 2011, 108, 3803-3808. [CrossRef] [PubMed]

7. Funaoka, M. A new type of phenolic lignin-based network polymer with the structure-variable function composed of 1,1-diarylpropane units. Polym. Int. 1998, 47, 277-290. [CrossRef]

8. Mikame, K.; Funaoka, M. Polymer structure of lignophenol I-Structure and function of fractionated lignophenol-. Polymer 2006, 38, 585-591. [CrossRef]

9. Funaoka, M.; Fukatsu, S. Characteristics of lignin structural conversion in a phase-separative reaction system composed of cresol and sulfuric acid. Holzforschung 1996, 50, 245-252. [CrossRef]

10. Aberu, H.D.S.; Freire, M.D.F.I. Methoxyl content determination of lignins by ${ }^{1} \mathrm{H}$ NMR. Anais da Academia Brasileira de Ciencias 1995, 67, 379-382.

11. Mousavioun, P.; Doherty, W.O.S. Chemical and thermal properties of fractionated bagasse soda lignin. Ind. Crop. Prod. 2010, 31, 52-58. [CrossRef]

12. Kim, H.; Ralph, J.; Akiyama, T. Solution-state 2D NMR of ball-milled plant cell wall gels. Bioenerg. Res. 2008, 1, 56-66. [CrossRef]

13. Wen, J.L.; Sun, Z.J.; Sun, R.C. Structural characterization of alkali-extractable lignin fractions from bamboo. J. Biobased Mater. Bioenergy 2010, 4, 1-18. [CrossRef]

14. Del Río, J.C.; Rencoret, J.; Prinsen, P.; Martínez, Á.T.; Ralph, J.; Gutiérrez, A. Structural characterization of wheat straw lignin as revealed by analytical pyrolysis, 2D-NMR, and reductive cleavage methods. J. Agric. Food Chem. 2012, 60, 5922-5935. [CrossRef] [PubMed]

15. Funaoka, M. Sequential transformation and utilization of natural network polymer "LIGNIN". React. Funct. Polym. 2013, 73, 396-404. [CrossRef]

16. Ren, H.; Funaoka, M. Potential of herbaceous lignocellulosics as industrial raw materials. Trans. Mater. Res. Soc. Jpn. 2009, 34, 727-730. [CrossRef]

17. Ren, H. Potential of Bamboo as Industrial Raw Materials. Ph.D. Thesis, Mie University, Mie, Japan, September 2008.

18. Ralph, J.; Lapierre, C.; Lu, F.; Marita, J.M.; Pilate, G.; Van Doorsselaere, J.; Boerjan, W.; Jouanin, L. NMR evidence for benzodioxane structures resulting from incorporation of 5-hydroxyconiferyl alcohol into lignins of O-methyl-transferase-deficient poplars. J. Agric. Food Chem. 2001, 49, 86-91. [CrossRef] [PubMed]

19. Lu, F.; Marita, J.M.; Lapierre, C.; Jouanin, L.; Morreel, K.; Boerjan, W.; Ralph, J. Sequencing around 5-hydroxyconiferyl alcohol-derived units in caffeic acid $O$-methyltransferase-deficient poplar lignins. Plant Physiol. 2010, 153, 569-579. [CrossRef] [PubMed]

20. Samuel, R.; Pu, Y.Q.; Jiang, N.; Fu, C.X.; Wang, Z.Y.; Ragauskas, A. Structural characterization of lignin in wild-type versus COMT down-regulated switchgrass. Front. Energy Res. 2014, 1, 1-9. [CrossRef]

(C) 2018 by the authors. Licensee MDPI, Basel, Switzerland. This article is an open access article distributed under the terms and conditions of the Creative Commons Attribution (CC BY) license (http://creativecommons.org/licenses/by/4.0/). 